\title{
All-Terrain Vehicle-Related Injuries and Hospitalization: An Examination of the Influence of Age and Alcohol or Drugs
}

\author{
Shelby Bohl*,1, Manoj Sharma ${ }^{1,2}$ and Chester Jones ${ }^{1,3}$ \\ ${ }^{1}$ Walden University, ${ }^{2}$ University of Cincinnati, ${ }^{3}$ University of Arkansas, USA
}

\begin{abstract}
All-terrain vehicle (ATV) related injuries are a significant source of morbidity, mortality, disability, and hospitalization, and serious injuries among the elderly are increasing. In addition, alcohol and drug use are prevalent among those injured in ATV-related incidents. However, studies indicate varying alcohol and drug use patterns among age groups and less attention has been paid to the experience of older adults and to the influence of substance abuse (alcohol or drug involvement). Therefore, the purpose of this study was to examine the relationship between age, substance abuse and hospitalization resulting from ATV incidents among injured adults over the age of 21 (legally old enough to consume alcohol). A secondary purpose of this study was to explore the relationships between age and substance abuse, substance abuse and injured body sites, and age and injured body sites. Using a cross-sectional, quantitative approach and archival data from the National Electronic Injury Surveillance System (NEISS) from 2007, 1884 incidents were evaluated and results of multiple logistic regression analysis indicated that age and substance abuse add independent information in predicting the odds of hospitalization. Using the chi-square test, similar substance abuse involvement among young, middle-aged and older adults was found and differences in the distribution of injured body sites existed between those with and without substance abuse and between the three age groups. The results of this study suggest the need for age-specific prevention, specialized safety training for older adults, and more aggressive enforcement of drinking and driving restrictions while operating ATVs in order to reduce deaths, disabilities, and considerable financial costs associated with ATV-related hospitalizations.
\end{abstract}

Keywords: All-terrain vehicle injuries, all-terrain vehicle accidents, all-terrain vehicle, ATV, ATV-related injuries, injuries, injury, older adults, elderly, substance abuse, alcohol, intoxication, drugs, hospitalization.

\section{INTRODUCTION}

Injuries and deaths resulting from all-terrain vehicle (ATV) incidents are a preventable public health issue and contribute to substantial morbidity and mortality, with an estimated 150,900 emergency room treated injuries annually and an estimated risk of death of 1.0 per 10,000 ATVs in use [1]. Loss of productivity, medical care costs, and disability payments resulting from ATV-related injuries are a significant burden on Americans. Helmkamp and colleagues reported an estimated $\$ 3.5$ billion dollars of "lifetime economic costs" in 2005 [2] and adult medical costs for ATV-related incidents were found to increase between 2000 and 2005 from $\$ 1.8$ million to $\$ 2.2$ million in persons over the age of 15 [2]. In addition, a considerable amount of financial costs associated with hospitalizations are passed to the public, with publicly funded insurance accounting for $19 \%$ or $\$ 220$ million in costs and another $12 \%$ from the uninsured [3].

ATV-related incidents occur among a broad range of ages, from very young children to old adults. However, recent studies suggest a growing trend in ATV use among the elderly $[3,4]$ and greater mortality risk compared to their younger counterparts $[4,5]$. In West Virginia, a two-fold increase in fatality rates was found among older adults between 2005 and 2007 [4] and persons older than 60 had a

*Address correspondence to this author at the Walden University, USA; Tel: (805) 776-3571; E-mail: shelby.bohl@waldenu.edu higher risk of mortality compared to persons younger than 60 , indicating that older age was an independent predictor of mortality [5]. One reason for older riders being at increased risk may in part be due to physical characteristics (such as decreased reaction time and possible visual limitations), which uniquely increase their risk of accidents and injury $[4$, $6,7]$. However, unlike the pediatric and youth populations, which are at increased risk due to age, age for older adults may also contribute to worse outcomes. Once hospitalized, older age is associated with worse clinical presentation and recovery, greater hospital length of stays $[6,8]$, more frequent discharge to another care facility, and death while hospitalized [9]. In addition, varying results regarding the anatomical position of injuries among older adults exist. Most researchers found that older adults have more frequent trunkal or chest injuries and less head or neck injuries than their younger counterparts do [4, 8-10]. However, others found that the distribution of injuries for hospitalized patients were similar for older adults compared to those younger than 60 [6].

In addition to the effects of age on ATV-related incidents, alcohol and drug use have been found to be prevalent during ATV incidents, exacerbating the inherent dangers of ATV operation by impairing driving ability. Studies reporting the frequency of alcohol or drug use among fatal incidents found between $41 \%$ and $58 \%$ of incidents involved alcohol or drugs $[4,11,12]$. In addition, Balthrap, Nyland, and Roberts [13] reported alcohol involvement $7 \%$ to $33 \%$ of the time, with an average 
frequency of $10.5 \%$ and several other studies conducted at level I trauma centers reported alcohol or drug use ranging from $6.7 \%$ to $56 \%[8,14,15]$. In addition, Conner and colleagues found that for both inpatient and outpatient treated ATV incidents, $12.4 \%$ of all incidents involved alcohol [10]. Despite the known prevalence among ATV incidents, several researchers have reported varying alcohol and drug use patterns among ATV user age groups, with some reporting similar use between the young and old [8] and others reporting greater frequency among the younger age groups $[4,6]$. In addition, most studies have not assessed age-specific usage patterns among adults legally old enough to consume alcohol (21 years of age or older), and most only evaluated the relationship using dichotomized age groups of young versus old. Other modes of transportation such as motorcycles and automobiles, however, have established the relationship between alcohol use and severe or fatal crashes $[16,17]$ and older adults involved in fatal motor vehiclerelated incidents have the lowest prevalence of intoxication than other adult age groups 21 years of age and older.

ATV injuries sometimes require hospitalization rather than outpatient emergency department treatment. In studies that have reported hospitalization status after ATV injury, $15 \%$ to $16 \%$ required hospital admission as opposed to outpatient emergency room treatment $[10,18]$. In terms of inpatient versus outpatient costs, ATV-related inpatient incidents are more costly averaging $\$ 22,000$ per admission and $\$ 1,700$ for outpatient-treated injuries [10]. In addition, ATV-related hospitalizations reportedly increased by an estimated $90 \%$ over the 5-year period between 2000 and 2005 , and an estimated $8 \%$ of the hospitalizations were among persons older than 60 [3]. However, these studies did not report the effect of age and alcohol or drug involvement (substance abuse) on hospitalization and no recent studies in which the proportion of patients admitted to the hospital versus treated in the emergency department and released for an ATV-related injury in which age and substance abuse status were known and the relationship reported were identified. Because hospitalization rates are increasing [3], and incidents that result in hospitalization are more costly than outpatient-related incidents [10], understanding the influence of age and substance abuse on hospitalization is important and may provide information to more effectively prevent injuries and hospitalizations.

Therefore, the primary purpose of this study was to examine the effect of age and substance abuse (alcohol or drug involvement) among adult riders involved in an ATV incident using 2007 data from the National Electronic Injury Surveillance System (NEISS). The main purpose of this study was to determine if an association between age and substance abuse and ATV-related injuries that result in hospitalization exists, with a special interest in examining the characteristics among older adults. Given mixed results, limited data, variations in study populations, and fewer studies among the elderly, this study also examined the distribution of injured body sites resulting from ATV-related incidents and determined if the distribution of those injured body sites were different for those who had incidents that involved either alcohol or drugs (substance abuse) compared to those who had incidents that did not involve alcohol or drugs. In addition, patients were categorized as young adults (21-35 years), middle-aged adults (36-50 years) and older adults (51 years and older) and the percentage of patients who had alcohol or drugs documented in their injury report were compared between the three adult age categories, thereby providing more granular information about adult substance abuse patterns. The study also included a comparison of the distribution of injured body sites between the three age groups.

\section{MATERIAL AND METHODOLOGY}

\section{Study Design and Sample}

The study was a quantitative cross-sectional design using 2007 archived data from the NEISS database. The NEISS collects injury data from a probability sample of over 5300 hospitals in the United States [22]. The NEISS sample includes four hospital sizes (small, medium, large, and very large) and pediatric hospitals, all with at least six or more beds and an emergency department $[20,21]$. The current NEISS sample includes 100 U.S. hospitals $[20,21]$. The NEISS database was chosen because it provides injury data and hospitalization status (disposition) from a diverse national sample of hospitals as opposed to data from a single institution or a trauma-only database. In addition, the sampling frame included hospitals in various geographic areas, making study results more generalizable than if the data were from a single center. The Consumer Product Safety Commission (CPSC) maintains the NEISS, and has been in place for more than 25 years [22]. When patients arrive at the emergency department of a NEISS hospital, the emergency personnel obtain pertinent information from the patient and record it in the medical record [22]. A NEISS coordinator conducts a daily review of emergency department records for eligible cases and enters data onto coding worksheets [22]. The staff enters data from the worksheet into the NEISS, and automatic edit checks for proper data format and completeness result during the data entry process $[19,22]$. To standardize reporting and coding of emergency data, the CPSC provides a coding manual with specific instructions on reporting cases into the system to increase the reliability and validity of the information in the database [22]. In addition, quality review of information in the NEISS database is an ongoing activity by the CPSC [23].

The study sample included incidents reported to the NEISS database between January 1, 2007 and December 31, 2007 for ages ranging from 21 to 120, and for ATV-related injuries corresponding to ATV product codes 3285 (three wheels only, exclusively off road), 3286 (four wheels, excluding dune buggies), 3287 (number of wheels not specified, excluding dune buggies) and 3296 (more than four wheels, excluding dune buggies). The following incidents were excluded: cases with a disposition equaling 5 (held for observation) or 8 (fatality, including DOA, died in hospital emergency department). Incidents with dispositions of 6 (left without being seen) and 9 (not recorded) were also excluded from the study sample. After applying these exclusions, 36 cases were excluded and the final study sample included 1,884 records meeting the above criteria. The rationale for exclusion of the disposition 'held for observation' is the incident may have either been an inpatient event (held for greater than 24 hours) or an outpatient event (held for less than 24 hours) and the NEISS database did not specify this information. Therefore, it was not possible to accurately 
categorize these dispositions according to hospitalization status. In addition, the NEISS database fails to differentiate between fatal events that occurred during treatment or on arrival. Incidents with fatal dispositions were also excluded because this disposition category does not necessarily equate to hospital admission. However, the need for hospitalization is likely had the subject survived a fatal incident.

\section{Variables and Coding}

The dependent variable in this study was hospitalization, measured on a categorical scale with two categories. If the disposition (the field in the NEISS database, which indicates the extent of injury as defined by the type of treatment received [22]) were recorded as either, 2 (treated and transferred to another hospital) or 4 (treated and admitted for hospitalization [within same facility]), the variable was coded as hospitalized. If the disposition were recorded in the NEISS database as 1 (treated and released, or examined and released without treatment), the variable was coded as not hospitalized. If the disposition was 5 (held for observation), 6 (left without being seen), 8 (fatality, including DOA, died in hospital emergency department), or 9 (not recorded), the case was excluded.

The two independent variables for this study were age and substance abuse. Age included the subject's age in years at the time of their ATV incident, measured on a continuous scale. The narrative field of the NEISS database included pertinent information about what the person was doing at the time of the ATV-related incident [22]. Information about alcohol or drug involvement was abstracted from this narrative field to define each incident's substance abuse status. For the purpose of this study, documentation of any alcohol or drug involvement (illicit or prescription drug abuse) in the narrative field indicated the presence of substance abuse, measured on a categorical scale with 2 categories. If the narrative indicated either alcohol or drugs or both were involved, the variable was coded as substance abuse. Otherwise, the variable was coded no substance abuse. Blood alcohol or urine drug levels were not an available, coded field in the NEISS database. In addition, a gender variable was created from the sex variable in the NEISS database, where female was coded as 0 and male was coded as 1 .

The NEISS database included 4 racial categories: White,
Black, Other, and Not stated. The NEISS database also included the variable Diagnosis, which indicated the type of injury sustained based on the most severe injury if multiple injuries were present [22]. Incident Locale included the location of where the ATV-related incident took place and included: home, farm or ranch, street or highway, other public property, manufactured (mobile) home, industrial site, or school [22].

For the chi-square analyses, an age category variable was created to summarize the frequency distribution for age groups and included: young adults (21-35), middle-aged adults (36-50), and older adults (51 and older). Age categories used in prior research [8] among a similar population (those injured in ATV-related incidents) formed the basis for the age categories used in this study. In addition, a primary purpose of this study was to examine substance abuse patterns among adults legally old enough to consume alcohol, and therefore excluded persons under the age of 21 .

Prior to conducting the chi-square tests, the frequency distribution of injured body parts were first inspected to determine which body parts had a sufficient sample size to be compared between the two substance abuse groups and between adult age categories. Body parts were combined into meaningful groups for both the descriptive statistics and inferential testing, and records with missing data on the body part injured were excluded from the chi-square test. Table $\mathbf{1}$ describes the categories used to collapse the 26 different NEISS body parts into body site categories.

\section{Data Analyses}

The statistical package PASW 18.0 (SPSS) was used for all statistical analysis. All inferential statistical analyses performed were two-sided with a 5\% alpha level. The initial step of the data analyses included descriptive analysis for the following variables: age (by category), gender, race, disposition, hospitalization, substance abuse, and body site injured. In addition, although not required for the coding of key variables or included in any inferential analysis, the frequency distribution of the primary diagnosis and the location where the injury took place were summarized.

Multiple logistic regression analysis was employed to determine if age and substance abuse added independent

Table 1. Body Site Categorization

\begin{tabular}{|c|c|}
\hline NEISS Body Part (Code) & Collapsed Body Site Category for Study Analysis \\
\hline \hline Head (75) & Head \\
\hline Ear (94), Eyeball (77), Face (76), Mouth (88) & Neck \\
\hline Neck (89) & Arm/Shoulder (Upper extremity) \\
\hline Shoulder (30), Upper arm (80), Elbow (32), Lower arm (33), Wrist (34), Hand (82), Finger (92) & Upper trunk \\
\hline Upper trunk (31) & Lower trunk \\
\hline Lower trunk (79), Pubic region (38) & Leg/Foot (Lower extremity) \\
\hline Upper Leg (81), Knee (35), Lower leg (36), Ankle (37), Foot (83), Toe (93) & Other \\
\hline $25-50 \%$ of body (84), All parts of the body (85), Internal (00) & Cases excluded from the analysis \\
\hline Not Recorded (87) &
\end{tabular}


information in predicting hospitalization. The model included the variable of gender, but did not include two other potential control variables (race and location where the injury took place) due to significant missing data on these variables. Cross tabulations and the Pearson chi-square test were performed to test the relationships between substance abuse and age, age and injured body sites, substance abuse and injured body sites, and age and hospitalization.

\section{RESULTS}

\section{Age, Gender, and Race}

The age range of the study sample was 21 to 94 years, with a mean age of 34.5 years and standard deviation of 12.3 years. Young adults (21-35 years) accounted for the largest proportion of the study sample $(62.3 \%)$. Middle-aged adults (36-50 years) accounted for $27.1 \%$ and older adults (51 years and older) accounted for the smallest proportion of the sample $(10.6 \%)$.

The majority $(75.3 \%)$ of the subjects were male, and women accounted for just less than a quarter of the study sample $(24.7 \%)$. There are three primary racial group categories to which NEISS hospital staff may code: White, Black, and Other. The majority of the subjects were White (64.4\%), 3.7\% were Black, and 2.8\% reported Other as the race. In addition, a significant number of cases $(29.2 \%)$ did not have race stated in their record, thereby not allowing for inclusion of this variable in the inferential analysis.

\section{Disposition and Hospitalization Status}

The largest proportion $(86.2 \%)$ of the study sample were treated in the emergency department and released or examined in the emergency department and released without treatment (outpatient visits). There were $11.7 \%$ that required hospital admission within the same facility and another $2.1 \%$ that required treatment and transfer to another hospital (inpatient care). These dispositions resulted in $86.2 \%$ of subjects categorized as not hospitalized and $13.8 \%$ categorized as hospitalized.

\section{Substance Abuse Status}

Upon review of all 1,884 narratives for documentation of any alcohol or drug involvement, substance abuse was present in $4 \%$ of the study sample. Only 3 of the 75 narratives with documented substance abuse involved drugs. One report included both drug and alcohol abuse and 2 involved drugs alone: 1 report of smoking crack and 1 report of amphetamine use. The majority of the study sample (96\%) did not have substance abuse documented.

\section{Injured Body Site}

Table 2 presents the frequency distribution of key variables. The greatest numbers of injuries were to the upper extremities $(26.3 \%)$, followed by lower extremities $(21.1 \%)$, lower trunk (14.2\%), and upper trunk (13.4\%). Head injuries accounted for $12.7 \%$. There were fewer facial and neck injuries than other body parts, $6.8 \%$ and $4.3 \%$ respectively. Among the other injury category, all 11 cases $(0.6 \%)$ were injuries affecting greater than $25 \%$ of the body. Relatively few cases $(0.7 \%)$ had a code indicating that the primary body part was not recorded.
Table 2. Frequency Distribution of Key Variables

\begin{tabular}{|c|c|c|}
\hline Variable & Frequency & Percent \\
\hline \multicolumn{3}{|l|}{ Age Category } \\
\hline Young adults (21-35) & 1174 & 62.3 \\
\hline Middle-aged adults (36-50) & 511 & 27.1 \\
\hline Older adults (51 and older) & 199 & 10.6 \\
\hline \multicolumn{3}{|l|}{ Gender } \\
\hline Male & 1418 & 75.3 \\
\hline Female & 466 & 24.7 \\
\hline \multicolumn{3}{|l|}{ Race } \\
\hline White & 1213 & 64.4 \\
\hline Black & 69 & 3.7 \\
\hline Other & 52 & 2.8 \\
\hline Not stated & 550 & 29.2 \\
\hline \multicolumn{3}{|l|}{ Disposition } \\
\hline $\begin{array}{l}\text { Treated and released or examined } \\
\text { and released without treatment }\end{array}$ & 1624 & 86.2 \\
\hline $\begin{array}{l}\text { Treated and transferred to another } \\
\text { hospital }\end{array}$ & 40 & 2.1 \\
\hline $\begin{array}{l}\text { Treated and admitted for hospitalization } \\
\text { (within same facility) }\end{array}$ & 220 & 11.7 \\
\hline \multicolumn{3}{|l|}{ Hospitalization Status } \\
\hline Hospitalized & 260 & 13.8 \\
\hline Not hospitalized & 1624 & 86.2 \\
\hline \multicolumn{3}{|l|}{ Substance Abuse Status } \\
\hline Substance abuse & 75 & 4.0 \\
\hline No Substance abuse & 1809 & 96.0 \\
\hline \multicolumn{3}{|l|}{ Injured Body Site } \\
\hline Head & 239 & 12.7 \\
\hline Face & 128 & 6.8 \\
\hline Neck & 81 & 4.3 \\
\hline Arm/shoulder (Upper extremity) & 495 & 26.3 \\
\hline Upper trunk & 252 & 13.4 \\
\hline Lower trunk & 267 & 14.2 \\
\hline Leg/foot (Lower extremity) & 379 & 21.1 \\
\hline $\begin{array}{l}\text { Other (Multiple body parts, } \\
\text { Internal) }\end{array}$ & 11 & .6 \\
\hline Not recorded & 14 & .7 \\
\hline
\end{tabular}

Although not key variables of interest, Table $\mathbf{3}$ summarizes the frequency distribution of the primary diagnosis and incident locale (location where incidents took place). The most frequent diagnosis were fractures $(25.6 \%)$, 
Table 3. Frequency Distribution of Primary Diagnosis and Incident Locale

\begin{tabular}{|c|c|c|c|}
\hline Variable & & Frequency & Percent \\
\hline \multicolumn{4}{|c|}{$\overline{\text { Diagnosis }}$} \\
\hline & Burns, not specified & 1 & .1 \\
\hline & Amputation & 2 & .1 \\
\hline & Burns, thermal & 7 & .4 \\
\hline & Concussions & 54 & 2.9 \\
\hline & Contusions, abrasions & 469 & 24.9 \\
\hline & Crushing & 7 & .4 \\
\hline & Dislocation & 38 & 2.0 \\
\hline & Foreign body & 4 & .2 \\
\hline & Fracture & 482 & 25.6 \\
\hline & Hematoma & 13 & .7 \\
\hline & Laceration & 147 & 7.8 \\
\hline & Dental injury & 3 & .2 \\
\hline & Nerve damage & 1 & .1 \\
\hline & Internal organ injury & 151 & 8.0 \\
\hline & Puncture & 6 & .3 \\
\hline & Strain or sprain & 363 & 19.3 \\
\hline & Hemorrhage & 2 & .1 \\
\hline & Poisoning & 1 & .1 \\
\hline & Submersion (including drowning) & 1 & .1 \\
\hline & Avulsion & 4 & .2 \\
\hline & Dermatitis, conjunctivitis & 5 & .3 \\
\hline & Other, not stated & 123 & 6.5 \\
\hline \multicolumn{4}{|c|}{ Incident Locale } \\
\hline & Home & 424 & 22.5 \\
\hline & Farm/ranch & 21 & 1.1 \\
\hline & Street or highway & 118 & 6.3 \\
\hline & Other public property & 140 & 7.4 \\
\hline & Place of recreation or sports & 302 & 16.0 \\
\hline & Not recorded & 879 & 46.7 \\
\hline
\end{tabular}

contusions or abrasions $(24.9 \%)$, strains or sprains $(19.3 \%)$, followed by internal organ injuries $(8.0 \%)$. A large number of records $(46.7 \%)$ were missing information for incident locale, and for this reason the variable was not included in any inferential testing. However, among those with information reported, the greatest number of incidents occurred at home $(22.5 \%)$ and at places of recreation or sport $(16.0 \%)$.

\section{Hospitalization}

Table 4 presents the results of the multiple logistic regression analysis. The relationship between age, substance abuse, and hospitalization was tested using a multiple logistic regression model. Age and substance abuse were the independent variables, hospitalization was the dependent variable, and gender was included as a control variable. Males were more likely to be hospitalized than females $(O R=1.46, p=.032)$. The results indicated a statistically significant relationship $p<.001$, between age and hospitalization and between substance abuse and hospitalization $p<.001$, demonstrating that when controlling for gender, both age and substance abuse were predictors of hospitalization. When controlling for gender and substance abuse, the odds of hospitalization increased by $35 \%$ for every 10 -year increase in age $(O R=1.35)$. When controlling for gender and age, the odds of hospitalization was 5.60 times greater for those with substance abuse compared to those without substance abuse.

\section{Age and Substance Abuse}

Table 5 presents the results of the cross tabulation and chi-square statistic for age and substance abuse. There was no significant difference $(p=.217)$ between age and substance abuse. This result demonstrates that age was not associated with substance abuse and the frequency of substance abuse was independent of the age of the subject involved in the ATV-related incident. Young adults, middleaged adults, and older adults all had similar substance abuse involvement.

\section{Substance Abuse and Injured Body Site}

Table 6 presents the results of the cross tabulation and chi-square statistic for substance abuse and injured body site. The table indicates the number and percent of subjects with each type of injured body site for those with and without documented substance abuse. The total sample size for the analysis was 1,870. Subjects with missing values (not reported) for injured body part $(n=14)$ were excluded from the analysis. There was a statistically significant difference $(p<.001)$ in the distribution of injured body sites between

Table 4. Multiple Logistic Regression Analysis, Hospitalization

\begin{tabular}{|c|c|c|c|c|c|c|c|c|}
\hline & $\boldsymbol{B}$ & $\boldsymbol{S E}$ & $\boldsymbol{W a l d}$ & $\boldsymbol{d f}$ & $\boldsymbol{p}$ & $\boldsymbol{O R}$ & OR (Lower 95\%) & OR (Upper 95\%) \\
\hline \hline Gender & 0.38 & 0.17 & 4.61 & 1 & 0.032 & 1.46 & 1.03 & 1.22 \\
\hline Age (10 years) & 0.30 & 0.05 & 37.02 & 1 & 0.000 & 1.35 & 3.05 & 1.48 \\
\hline Substance Abuse & 1.72 & 0.25 & 48.82 & 1 & 0.000 & 5.60 & & 9.09 \\
\hline Constant & -3.32 & 0.24 & 188.92 & 1 & 0.000 & 0.04 & & \\
\hline
\end{tabular}

Note. $B$ is the regression coefficient for the constant; $S E$ is the standard error of the regression coefficient Wald reflects the chi-square statistic indicating the significance of individual coefficients; $d f$ are the degrees of freedom for the variable; $p$ indicates the p-value for the test statistic; $O R$ indicates the odds ratio. 
Table 5. Cross Tabulation and Chi-Square Results, Age and Substance Abuse

\begin{tabular}{|c|c|c|c|c|c|}
\hline & & & \multicolumn{2}{|c|}{ Substance Abuse } & \multirow[b]{2}{*}{ Total } \\
\hline & & & No Substance Abuse & Substance Abuse & \\
\hline \multirow[t]{9}{*}{ Age Category } & Young Adults & Count & 1133 & 41 & 1174 \\
\hline & & $\%$ within Age Category & $96.5 \%$ & $3.5 \%$ & $100.0 \%$ \\
\hline & & Standard Residual & 0.2 & -0.8 & \\
\hline & Middle Aged Adults & Count & 489 & 22 & 511 \\
\hline & & $\%$ within Age Category & $95.7 \%$ & $4.3 \%$ & $100.0 \%$ \\
\hline & & Standard Residual & -0.1 & 0.4 & \\
\hline & Older Adults & Count & 187 & 12 & 199 \\
\hline & & $\%$ within Age Category & $94.0 \%$ & $6.0 \%$ & $100.0 \%$ \\
\hline & & Standard Residual & -0.3 & 1.4 & \\
\hline \multirow[t]{3}{*}{ Total } & & Count & 1809 & 75 & 1884 \\
\hline & & Percent & $96.0 \%$ & $4.0 \%$ & $100.0 \%$ \\
\hline & Value & $d f$ & $\begin{array}{r}\text { Significance } \\
(2 \text {-sided })\end{array}$ & & \\
\hline Pearson Chi-Square & 3.06 (a) & 2 & 0.217 & & \\
\hline
\end{tabular}

Note. (a) 0 cells $(0.0 \%)$ have expected count less than 5 . The minimum expected count is 7.92 .

those with substance abuse and those without substance abuse. This result demonstrates that substance abuse was associated with injured body site and the frequency of injured body site was not independent of the substance abuse status of the subject involved in the ATV-related incident. Among those with head injuries, there were more subjects with substance abuse than expected. Among those with substance abuse, $40 \%$ had head injuries. In addition, among subjects with upper extremity injuries (arm/shoulder), there were fewer subjects with substance abuse than expected. Among those with substance abuse, $14.7 \%$ had upper extremity injuries.

\section{Age and Injured Body Site}

Table 7 presents the results of the cross tabulation and chi-square statistic for age and injured body site. The table presents the number and percent of subjects with each type of injured body site for each age group. The total sample size

Table 6. Cross Tabulation and Chi-Square Results, Substance Abuse and Injured Body Site

\begin{tabular}{|c|c|c|c|c|c|c|c|c|c|c|c|}
\hline & & & \multicolumn{8}{|c|}{ Injured Body Site } & \multirow[b]{2}{*}{ Total } \\
\hline & & & Head & Face & Neck & $\begin{array}{r}\text { Upper } \\
\text { Extremity }\end{array}$ & $\begin{array}{l}\text { Upper } \\
\text { Trunk }\end{array}$ & $\begin{array}{l}\text { Lower } \\
\text { Trunk }\end{array}$ & $\begin{array}{r}\text { Lower } \\
\text { Extremity }\end{array}$ & Other & \\
\hline \multirow[t]{6}{*}{$\begin{array}{l}\text { Substance } \\
\text { Abuse }\end{array}$} & $\begin{array}{l}\text { No } \\
\text { Substance } \\
\text { Abuse }\end{array}$ & Count & 209 & 120 & 79 & 484 & 244 & 262 & 387 & 10 & 1795 \\
\hline & & $\begin{array}{l}\% \text { within } \\
\text { Substance } \\
\text { Abuse }\end{array}$ & $11.6 \%$ & $6.7 \%$ & $4.4 \%$ & $27.0 \%$ & $13.6 \%$ & $14.6 \%$ & $21.6 \%$ & $0.6 \%$ & $100.0 \%$ \\
\hline & & Standard Residual & -1.3 & -0.3 & .1 & 0.4 & 0.1 & 0.4 & 0.3 & -0.2 & \\
\hline & $\begin{array}{l}\text { Substance } \\
\text { Abuse }\end{array}$ & Count & 30 & 8 & 2 & 11 & 8 & 5 & 10 & 1 & 75 \\
\hline & & $\begin{array}{l}\% \text { within } \\
\text { Substance } \\
\text { Abuse }\end{array}$ & $40.0 \%$ & $10.7 \%$ & $2.7 \%$ & $14.7 \%$ & $10.7 \%$ & $6.7 \%$ & $13.3 \%$ & $1.3 \%$ & $100.0 \%$ \\
\hline & & $\begin{array}{l}\text { Standard } \\
\text { Residual }\end{array}$ & 6.6 & 1.3 & -0.7 & -2.0 & -0.7 & -1.7 & -1.5 & 0.8 & \\
\hline \multirow[t]{3}{*}{ Total } & & Count & 239 & 128 & 81 & 495 & 252 & 267 & 397 & 11 & 1870 \\
\hline & & Percent & $12.8 \%$ & $6.8 \%$ & $4.3 \%$ & $26.5 \%$ & $13.5 \%$ & $14.3 \%$ & $21.2 \%$ & $0.6 \%$ & $100.0 \%$ \\
\hline & Value & $d f$ & \multicolumn{2}{|c|}{$\begin{array}{r}\text { Significance } \\
\text { (2-sided) }\end{array}$} & \multicolumn{3}{|c|}{$\begin{array}{r}\text { Monte Carlo Significance } \\
(2-\text { sided })\end{array}$} & & & & \\
\hline $\begin{array}{l}\text { Pearson } \\
\text { Chi- } \\
\text { Square }\end{array}$ & 58.23 (a) & 7 & & .000 & & & .000 (b) & & & & \\
\hline
\end{tabular}

Note. (a) 2 cells (12.5\%) have expected count less than 5. The minimum expected count is .44. (b) Based on 10000 sampled tables with starting seed 624387341 . 
Table 7. Cross Tabulation and Chi-Square Results, Age and Injured Body Site

\begin{tabular}{|c|c|c|c|c|c|c|c|c|c|c|c|}
\hline & & & \multicolumn{8}{|c|}{ Injured Body Site } & \multirow[b]{2}{*}{ Total } \\
\hline & & & Head & Face & Neck & $\begin{array}{c}\text { Upper } \\
\text { Extremity }\end{array}$ & $\begin{array}{l}\text { Upper } \\
\text { Trunk }\end{array}$ & $\begin{array}{l}\text { Lower } \\
\text { Trunk }\end{array}$ & $\begin{array}{c}\text { Lower } \\
\text { Extremity }\end{array}$ & Other & \\
\hline \multirow[t]{9}{*}{$\begin{array}{c}\text { Age } \\
\text { Category }\end{array}$} & $\begin{array}{l}\text { Young } \\
\text { Adults }\end{array}$ & Count & 152 & 88 & 53 & 330 & 109 & 167 & 263 & 4 & 1166 \\
\hline & & $\begin{array}{c}\% \text { within Age } \\
\text { Category }\end{array}$ & $13.0 \%$ & $7.5 \%$ & $4.5 \%$ & $28.3 \%$ & $9.3 \%$ & $14.3 \%$ & $22.6 \%$ & $0.3 \%$ & $100.0 \%$ \\
\hline & & $\begin{array}{l}\text { Standard } \\
\text { Residual }\end{array}$ & 0.2 & 0.9 & 0.4 & 1.2 & -3.8 & 0.0 & 1.0 & -1.1 & \\
\hline & $\begin{array}{l}\text { Middle- } \\
\text { Aged Adults }\end{array}$ & Count & 60 & 29 & 23 & 123 & 101 & 67 & 100 & 5 & 508 \\
\hline & & $\begin{array}{c}\% \text { within Age } \\
\text { Category }\end{array}$ & $11.8 \%$ & $5.7 \%$ & $4.5 \%$ & $24.2 \%$ & $19.9 \%$ & $13.2 \%$ & $19.7 \%$ & $1.0 \%$ & $100.0 \%$ \\
\hline & & $\begin{array}{l}\text { Standard } \\
\text { Residual }\end{array}$ & -0.6 & -1.0 & 0.2 & -1.0 & 3.9 & -0.6 & -0.8 & 1.2 & \\
\hline & Older Adults & Count & 27 & 11 & 5 & 42 & 42 & 33 & 34 & 2 & 196 \\
\hline & & $\begin{array}{c}\% \text { within Age } \\
\text { Category }\end{array}$ & $13.8 \%$ & $5.6 \%$ & $2.6 \%$ & $21.4 \%$ & $21.4 \%$ & $16.8 \%$ & $17.3 \%$ & $1.0 \%$ & $100 \%$ \\
\hline & & $\begin{array}{l}\text { Standard } \\
\text { Residual }\end{array}$ & 0.4 & -0.7 & -1.2 & -1.4 & 3 & 0.9 & -1.2 & 0.8 & \\
\hline \multirow[t]{3}{*}{ Total } & & Count & 239 & 128 & 81 & 495 & 252 & 267 & 397 & 11 & 1870 \\
\hline & & Percent & $12.8 \%$ & $6.8 \%$ & $4.3 \%$ & $26.5 \%$ & $13.5 \%$ & $14.3 \%$ & $21.2 \%$ & $.6 \%$ & $100.0 \%$ \\
\hline & Value & $d f$ & \multicolumn{2}{|c|}{$\begin{array}{l}\text { Significance } \\
\text { (2-sided) }\end{array}$} & \multicolumn{3}{|c|}{$\begin{array}{c}\text { Monte Carlo Significance } \\
\text { (2-sided) }\end{array}$} & & & & \\
\hline $\begin{array}{l}\text { Pearson Chi- } \\
\text { Square }\end{array}$ & 58.59 (a) & 14 & \multicolumn{2}{|c|}{.000} & \multicolumn{3}{|c|}{$.000(\mathrm{~b})$} & & & & \\
\hline
\end{tabular}

Note. (a) 2 cells (8.3\%) have expected count less than 5. The minimum expected count is 1.15. (b) Based on 10000 sampled tables with starting seed 2000000.

for the analysis was 1,870 . Subjects with missing values (not reported) for injured body part $(N=14)$ were excluded from the analysis. There was a statistically significant difference $(p<.001)$ in the distribution of injured body sites between young adults, middle-aged adults and older adults. This result demonstrates that age was associated with injured body site and the frequency of injured body site was not independent of the age of the subject involved in the ATVrelated incident. A greater percentage of older adults $(21.4 \%)$ and middle-aged adults $(19.9 \%)$ had upper trunk injuries as compared to young adults $(9.3 \%)$.

\section{Age and Hospitalization}

A chi-square test was also conducted to determine if there was a difference in the proportion of hospitalizations by age categories (young adults, middle-aged adults, and older adults). There was a statistically significant difference $(p<.001)$ in the distribution of hospitalization among young adults, middle-aged adults and older adults. This result demonstrates that age was associated with hospitalization and the frequency of hospitalization was not independent of the age of the subject involved in the ATV-related incident. Among young adults (21-35), 10.7\% were hospitalized compared to $26.6 \%$ among older adults (51 and older). Table 8 presents the results of the cross tabulation and chi-square statistic for age and hospitalization.

\section{DISCUSSION}

The study sample involved a wide age range from 21 to 94 years, indicating that ATV incidents do not discriminate by age and very old persons are involved in ATV incidents. Although the smallest percent $(10.6 \%)$ of the sample were older adults (51 years and older), the results indicated that older age was an important predictor of hospitalization and was associated with key variables. Consistent with prior research reporting on gender [4, 6, 12] and race [24], more males were involved in incidents than females, and Whites accounted for the largest racial group in this study. Only 4\% of the study sample had documented substance abuse (either alcohol or drug involvement). Only $2(2.67 \%)$ of these cases were related to drugs alone indicating that the presence of substance abuse in this study primarily represented alcohol rather than drug involvement. Prior studies showed a broad range in the prevalence of substance abuse, $6.7 \%$ [14] to $56 \%$ [15] however, compared to the average frequencies $(10.5 \%$ and $12.4 \%)$ previously reported by researchers $[10$, 14], ATV incidents in this study involved a somewhat lower frequency $(4 \%)$ of substance abuse. The majority of incidents in the study involved outpatient visits versus inpatient hospital treatment (13.8\%). These proportions of hospitalization were similar to those previously reported by Rodgers and Adler in 2001 [18] using the NEISS database and in the study by Conner and colleagues in 2008 [10]. 
Table 8. Cross Tabulation and Chi-Square Results, Age and Hospitalization

\begin{tabular}{|c|c|c|c|c|c|}
\hline & & & \multicolumn{2}{|c|}{ Hospitalization } & \multirow[b]{2}{*}{ Total } \\
\hline & & & Not Hospitalized & Hospitalized & \\
\hline \multirow[t]{9}{*}{ Age Category } & Young Adults & Count & 1048 & 126 & 1174 \\
\hline & & $\%$ within Age Category & $89.3 \%$ & $10.7 \%$ & $100.0 \%$ \\
\hline & & Standard Residual & 1.1 & -2.8 & \\
\hline & Middle Aged Adults & Count & 430 & 81 & 511 \\
\hline & & $\%$ within Age Category & $84.1 \%$ & $15.9 \%$ & $100.0 \%$ \\
\hline & & Standard Residual & -0.5 & 1.2 & \\
\hline & Older Adults & Count & 146 & 53 & 199 \\
\hline & & $\%$ within Age Category & $73.4 \%$ & $26.6 \%$ & $100.0 \%$ \\
\hline & & Standard Residual & -1.9 & 4.9 & \\
\hline \multirow{2}{*}{\multicolumn{2}{|c|}{ Total }} & Count & 1624 & 260 & 1884 \\
\hline & & Percent & $86.2 \%$ & $13.8 \%$ & $100.0 \%$ \\
\hline & Value & $d f$ & $\begin{array}{l}\text { Significance } \\
(2-\text { sided })\end{array}$ & & \\
\hline Pearson Chi-Square & 38.64 (a) & 2 & 0.000 & & \\
\hline
\end{tabular}

\section{Hospitalization}

The results demonstrated that both age and substance abuse increased the odds of hospitalization. Research among motor vehicle incidents indicated similar findings, that substance abuse (driving while under the influence) increases the risk of hospitalization [25]. In addition, whereas the elderly make up a smaller proportion of the general population, they are accountable for an estimated $35 \%$ of all hospitalizations in the U.S. [26], demonstrating increased risk of hospitalization with increasing age. In addition, alcohol-related illness or injuries are among the top ten reasons persons are hospitalized [26] and alcohol use is well established to increase the risk of many types of unintentional injuries [27, 28].

\section{Age and Substance Abuse}

Substance abuse patterns were similar between young adults (21-35 years), middle-aged adults (36-50 years) and older adults (51 years and older). This finding is consistent with recent research [8], but inconsistent with previous findings $[4,6]$. Mixed results may be due to variations in study populations or varying age ranges used to define age categories. In contrast to ATV incidents in this study, older adults involved in fatal motor vehicle-related incidents have the lowest prevalence of intoxication than other adult age groups [29]. Younger adults (21-24 years) have the highest percent of alcohol-related incidents followed by 25-34 year olds [29]. These patterns were not observed among the ATV population in this study, suggesting different substance abuse patterns by age groups among ATV users than those involved in motor vehicle incidents.

\section{Substance Abuse and Injured Body Site}

Substance abuse was associated with injured body site and there were a greater percentage of head injuries among those with substance abuse than those without substance abuse. This finding is somewhat consistent with the most common injuries (head and spinal cord) among ATV traumas reported by Sibley and Tallon [15], in which $56 \%$ of the incidents involved alcohol. However, the authors did not specifically assess the relationship between substance abuse and various injured body sites. Helmet status was not available for analysis in this study. However, prior research [15] has indicated that helmet use was not associated with blood alcohol concentrations, suggesting that helmet use in this study may not have been an important variable or related to the greater number of injuries to the head among those with substance abuse. In addition, the study finding is consistent with various modes of injuries other than ATVrelated incidents. In persons with injuries requiring hospitalization and that involved alcohol, Howland, Bell, and Hollander [30] also found that head injuries were more common than other types of injuries. In addition, persons with substance abuse had fewer upper extremity injuries than those with no substance abuse. This finding is somewhat consistent with other research [30] for various modes of injuries that found greater extremity injuries among those without alcohol involvement compared to those with alcohol involvement. Those with substance abuse involvement may have slower reaction time or decreased motor skills [27] and therefore may have been less likely to use protective responses such as breaking a fall with the upper extremities, which is a common reaction and mechanism of protection in other modes of injuries such as falls [31].

\section{Age and Injured Body Site}

Results indicated that age was associated with injured body site. A greater percentage of older adults and middleaged adults had upper trunk injuries as compared to young adults. The findings are consistent with two prior studies [4, 8 ] among those fatally injured or admitted for traumatic care 
in which the anatomical position of injuries varied by age, with more frequent trunkal injuries found among the elderly or older adults. Testerman [8] also reported greater injury severity for injuries to the chest among patients 51 and older. In three studies $[4,6,12]$, the mechanism of fatal injury among older riders was primarily due to rollovers as compared to collisions, which was more common in younger riders suggesting that greater trunkal injuries found among older adults may be due to variations in crash dynamics. If older adults are more likely to have rollovers, it is important that safety training address this finding and that emergency medical practitioners properly triage for trunkal injuries that may result in internal organ injuries. However, significantly fewer head or neck injuries among older adults were not found. Prior research $[4,8,9]$ shows somewhat mixed results regarding the age distribution of these injured body parts; however, the majority of the studies reported fewer head or neck injuries among older age groups.

\section{Limitations}

This study examined the experience of subjects evaluated for ATV-related incidents in U.S. emergency room departments, and therefore may not be representative of the experience of all persons injured as a result of ATVs including those that died at the scene or sought treatment in outpatient facilities other than hospitals. In addition, certain data were not available for the multiple regression analysis in this study due to the limitations of the NEISS database. Race, incident locale, socioeconomic status, helmet use, crash type, or significant co-morbidities were not available for analysis either due to significant missing data or not being captured in the system. The low prevalence of alcohol or drug involvement found in this study (4\%) may be due to underreporting of substance abuse within the NEISS database because alcohol or drug use is no longer a specific coded field captured by the system. Substance abuse was derived from the narrative fields within the NEISS database, and it is possible that hospitals failed to report substance abuse in the incident narratives. However, despite this limitation, there is no reason to believe that missing data or underreporting on alcohol or drug use (substance abuse) would be biased according to hospitalization status, and therefore had an adverse effect on testing the relationship between substance abuse and hospitalization. In addition, it is not clear that underreporting occurred. Also, studies that reported a higher prevalence of alcohol or drug use [4, 11, 12] involved fatal injuries, whereas this study sample did not include fatal incidents. If underreporting on alcohol or drug use occurred in this study, the study sample might not be representative of all persons who had substance abuse.

\section{CONCLUSIONS}

This study examined patients admitted to the hospital versus treated in the emergency department and released for an ATV-related injury in which age and substance abuse status were known. Prior studies have not reported these relationships nor have they abstracted information on alcohol or drug involvement from the NEISS database narratives. In addition, most prior research has not focused on age-specific substance abuse patterns, or has primarily reported alcohol/drug involvement using dichotomized age groups of young versus old. This study provided more granular information about adult substance abuse patterns, injured body sites, and hospitalization.

Prior research indicate that injuries and deaths resulting from ATV incidents are a significant public health issue, substance abuse is commonly involved in incidents $[4,8,11$ 15], and older adults may be an increasingly vulnerable population $[4,5,8]$. Injuries and deaths have substantial financial ramificants including loss of productivity, medical care costs, and disability payments [3] and hospitalizations are associated with greater average costs than injuries treated on an outpatient basis [10]. This study's findings suggest that both increasing age (older age) and the presence of substance abuse significantly increases the likelihood of hospitalization. Therefore, it is critical to prevent alcohol or drug use while operating ATVs. In addition, study results also suggest that all ages of ATV users operated ATVs while impaired. However, older riders typically have poorer outcomes once hospitalized [8], are more likely to die once hospitalized, and are more frequently discharged to another care facility [9]. Therefore, it is paramount that older adults are perceived as an important group for targeting injury prevention strategies so that both injury burden and costs associated with hospitalization are reduced. Public health prevention strategies and legislative actions should consider older age and substance abuse as important variables in preventing ATV-related injuries requiring hospitalization.

\section{ACKNOWLEDGEMENTS}

Dr. Ji Shen, and Dr. Lawrence Fulton of Walden University are acknowledged for providing guidance and review of this research study. In addition, Steve Creech is acknowledged for his input.

\section{TRIAL REGISTRATION}

Not applicable

\section{CONFLICT OF INTEREST}

There are no known conflicts of interest in this study.

\section{REFERENCES}

[1] U.S. Consumer Product Safety Commission. All-terrain vehicles (ATVs) project status report. Bethesda (MD): US Consumer Product Safety Commission; 2008, Feb [cited Jun 11 2009]. Available from: http://www.cpsc.gov/library/foia/foia08/brief/ATV ProjectStatusReport.pdf.

[2] Helmkamp JC, Aitken ME, Lawrence BA. ATV and bicycle deaths and associated costs in the United States, 2000-2005. Public Health Rep 2009; 124: 409-18.

[3] Helmkamp JC, Furbee PM, Coben JH, Tadros A. All-terrain vehicle-related hospitalizations in the United States, 2000-2004. Am J Prev Med 2008; 34(1): 39-45.

[4] Helmkamp JC, Carter MW. ATV deaths among older adults in West Virginia: Evidence suggesting that "60 is the new 40!". South Med J 2009; 102(5): 465-9.

[5] Deladisma AM, Parker W, Medeiros R, Hawkins M. All-terrain vehicle trauma in the elderly: An analysis of a national database. Am Surg 2008; 74(8): 767-9.

[6] Adams BD, Medeiros R, Dereska P, Hawkins M. Geriatric allterrain vehicle trauma. Am Surg [serial online] 2004 [cited 27 Mar 2009]; 70(4): 329-32.

[7] Iowa State University Extension. Safety tips for farming with limitations due to aging [Internet]. 2009. [cited 18 Jul 2009]. Available from: http://www.extension.iastate.edu/ agrability/safetytips.html

[8] Testerman GM. Increased all-terrain vehicle crash accidents in older riders. South Med J 2009; 102(5): 461-4. 
[9] Walling B, Tadros A, Davis S, Helmkamp J. ATV accidents and the elderly: National trends and implications for emergency medicine. Ann Emerg Med [abstract] 2008; 52(4 Suppl): S156.

[10] Conner KA, Huiyun X, Groner JI, Smith GA. Using data linkage to assess the impact of motorized recreational vehicle-related injuries in Ohio. J Saf Res 2008; 39: 469-75.

[11] Hall AJ, Bixler D, Helmkamp JC, Kraner JC, Kaplan JA. Fatal allterrain vehicle crashes: Injury types and alcohol use. Am J Prev Med 2009; 36(4): 311-6.

[12] Helmkamp JC. All-terrain vehicle-related deaths among the West Virginia elderly, 1985-1998. Am J Public Health 1999; 89(6): $1263-4$.

[13] Balthrop PM, Nyland J, Roberts CS. Risk factors and musculoskeletal injuries associated with all-terrain vehicle accidents. J Emerg Med 2009; 36(2): 121-31.

[14] Bansal V, Fortlage D, Lee J, Kuncir E, Potenza B, Coimbra R. A 21-year history of all-terrain vehicle injuries: Has anything changed? Am J Surg 2008; 195: 789-92.

[15] Sibley A, Tallon J. Major injury associated with all-terrain vehicle use in Nova Scotia: A 5-year review. J Can Assoc Emerg Physicians 2002; 4(4): 263- 267.

[16] Marottoli RA. Riding off into the sunset: Implications of an aging motorcyclist population. Ann Emerg Med 2002; 39(2): 196-7.

[17] National Highway Traffic Safety Association [NHTSA]. Traffic safety facts, 2005 data. Washington (DC): NHTSA's National Center for Statistics and Analysis; 2008 [cited 18 Jul 2009]. NHTSA Publication DOT HS 810 616. Available from: http://www-nrd.nhtsa.dot.gov/Pubs/810616.PDF

[18] Rodgers G, Adler P. Risk factors for all-terrain vehicle injuries: A national case-control study. Am J Epidemiol 2001; 153(11): 11128.

[19] U.S. Consumer Product Safety Commission. Consumer Product Safety Commission National Electronic Injury Surveillance System [Internet]. 2009. [cited 9 Jun 2009]. Available from http://www.cp sc.gov/cpscpub/pubs/3002.html

[20] U.S. Consumer Product Safety Commission. NEISS The National Electronic Injury Surveillance System tool for researchers. Bethesda (MD): U.S. Consumer Product Safety Commission Division of Hazard and Injury Data Systems; 2000 Mar [cited 11 Jun 2009]. Available from: http://www.cpsc.gov/LIBRARY/ne iss.html

[21] Schroeder T, Ault K. U.S. Consumer Product Safety Commission. The NEISS sample (design and implementation) 1997 to present.
Bethesda (MD): U.S. Consumer Product Safety Commission Division of Hazard and Injury Data Systems; 2001 Jun [cited 11 Jun 2009]. Available from: http://www.cpsc.gov/neiss/2001d0116b6.pdf.

[22] U.S. Consumer Product Safety Commission. NEISS coding manual. Bethesda (MD): U.S. Consumer Product Safety Commission; 2010 Jan [cited 15 Mar 2009]. Available from: http://search.cpsc.gov/query.html?qt=NEISS + coding + manual + and + Report + Legend \& charset $=$ iso- 8859 $1 \& \mathrm{col}=$ pubweb

[23] U.S. Consumer Product Safety Commission. U.S. Consumer Product Safety Commission information quality guidelines [Internet]. 2009 [cited18 Nov 2009]. Available from: http://www.cpsc.gov/library/infoguidelines.html

[24] Helmkamp J, Bixler D, Kaplan J, Hall A. All-terrain vehicle fatalities: West Virginia, 1999-2006. Morbid Mortal Wkly Rep 2008; 57(12): 312-5

[25] Karlsson G, Halldin J, Leifman A, Bergman H, Romelsjö A. Hospitalization and mortality succeeding drunk driving and risky driving. Alcohol 2003; 38(3): 281-6.

[26] Merrill CT, Elixhauser A. Hospitalization in the United States, 2002. Rockville (MD): Agency for Healthcare Research and Quality; 2005 [cited 3 Apr 2010]. HCUP Fact Book No. 6. AHRQ Publication No. 05-0056. Available from: http://www.ahrq.gov/ data/hcup/factbk6/factbk6.pdf

[27] Centers for Disease Control and Prevention. Alcohol and public health [Internet]. [cited 3 Apr 2010]. Available from: http://www. cdc.gov/alcohol/faqs.htm

[28] Centers for Disease Control and Prevention. Quick stats: General information on alcohol use and health [Internet]. 2008 [updated 6 Aug 2008; cited 3 Apr 2010]. Available from: http://www.cdc. gov/alcohol/quickstats/general info.htm

[29] National Highway Traffic Safety Association. Traffic safety facts, 2008 data. Washington (DC): NHTSA's National Center for Statistics and Analysis; 2009 [cited 18 Jul 2009]. NHTSA Publication DOT HS 811 162. Available from: http://www- nrd.nhtsa.dot gov/Pubs /811162.PDF

[30] Howland J, Bell NS, Hollander IE. Causes, types and severity of injury among army soldiers hospitalized with alcohol comorbidity. Addiction 2007; 102(9): 1411-20.

[31] Kim K, Ashton-Miller JA. Biomechanics of fall arrest using the upper extremity: Age differences. Clin Biomech 2003; 18(4): 3118.

This is an open access article licensed under the terms of the Creative Commons Attribution Non-Commercial License (http://creativecommons.org/licenses/bync/3.0/) which permits unrestricted, non-commercial use, distribution and reproduction in any medium, provided the work is properly cited. 